EXTENDED REPORT

\title{
Infliximab in active early rheumatoid arthritis
}

\author{
F C Breedveld, P Emery, E Keystone, K Patel, D E Furst, J R Kalden, E W St Clair, M Weisman, \\ J Smolen, P E Lipsky, R N Maini
}

Ann Rheum Dis 2004;63:149-155. doi: 10.1136/ard.2003.013961

See end of article for
authors' affiliations
....................
Correspondence to:
Professor F C Breedveld,
Department of
Rheumatology, University
of Leiden, Albinusdreef 2,
Postbus 9600,2300 RC
Leiden, The Netherlands;
f.c.breedveld@lumc.nl
Accepted
3 November 2003

\begin{abstract}
Objective: To examine the impact of the combination of infliximab plus methotrexate (MTX) on the progression of structural damage in patients with early rheumatoid arthritis (RA).

Methods: Subanalyses were carried out on data for patients with early RA in the Anti-TNF Therapy in RA with Concomitant Therapy (ATTRACT) study, in which 428 patients with active RA despite MTX therapy received placebo with MTX (MTX-only) or infliximab $3 \mathrm{mg} / \mathrm{kg}$ or $10 \mathrm{mg} / \mathrm{kg}$ every (q) 4 or 8 weeks with MTX (infliximab plus MTX) for 102 weeks. Early RA was defined as disease duration of 3 years or less; 82 of the 428 patients (19\%) met this definition. Structural damage was assessed with the modified van der Heijde-Sharp score. The changes from baseline to week 102 in total modified van der Heijde-Sharp score were compared between the infliximab plus MTX groups and the MTX-only group.

Results: The erosion and joint space narrowing scores from baseline to week 102 in the cohort of patients with early RA decreased significantly in each infliximab dose regimen compared with the MTX-only regimen. Consistent benefit was seen in the joints of both hands and feet.

Conclusions: Infliximab combined with MTX inhibited the progression of structural damage in patients with early RA during the 2 year period of treatment. Early intervention with infliximab in patients with active RA despite MTX therapy may provide long term benefits by preventing radiographic progression and preserving joint integrity.
\end{abstract}

$\mathrm{R}$ heumatoid arthritis (RA) is a chronic disease with the potential to cause substantial bone and cartilage damage and functional disability. In many patients, treatment with a disease modifying rheumatic drug (DMARD) is delayed. ${ }^{1-7}$ However, the inflammatory process continues to promote structural damage during the time from onset of symptoms to treatment. ${ }^{8-12}$ Magnetic resonance imaging studies demonstrate significant erosive changes in the joints of many patients, even at the time of diagnosis. ${ }^{13}{ }^{14}$ Recent studies have demonstrated that even a short delay in treatment may have long term consequences for the progression of joint damage. ${ }^{15-17}$ In a meta-analysis of 14 diverse, randomised controlled trials of DMARDs in RA, 53\% of patients who had a diagnosis within one year from onset of RA symptoms responded to treatment as compared with $35 \%$ of patients whose RA was diagnosed more than 10 years before treatment. ${ }^{18}$ During the past few years, treatment with traditional (non-biological) DMARDs has been the preferred treatment for early $\mathrm{RA}^{19-22}$ and there is evidence that an aggressive combination of potent DMARDs clearly improves clinical response and structural damage..$^{18} 8^{23-25}$ However, not all patients respond to DMARDs, and even some patients who demonstrate clinical improvement (signs and symptoms) with DMARD therapy may have continuing structural damage. ${ }^{26}$

In addition to studies with traditional DMARDs, some studies have evaluated the effect of early treatment with tumour necrosis factor (TNF) blocking agents. The results of a randomised, placebo controlled trial showed that the symptoms and retardation of joint damage in patients with early RA decreased more rapidly with etanercept than with methotrexate (MTX). ${ }^{27}$ In two recent studies, infliximab, an anti-TNF monoclonal antibody, was found to be effective for the treatment of early RA. ${ }^{28}{ }^{29}$ These findings are consistent with immunopathology studies of the synovium in RA demonstrating the production of TNF in the early as well as later stages of the disease. ${ }^{30}$
The results of the ATTRACT study at 30, 54, and 102 weeks, ${ }^{31-33}$ showed that infliximab plus MTX augments clinical and radiographic benefit in patients with active RA despite receiving treatment with MTX. The 54 week analysis showed that patients with RA of less than 3 years' duration who were treated with any of the infliximab plus MTX regimens had significantly greater improvement in radiographic scores than the MTX-only group. ${ }^{32}$ However, the longer term radiographic benefit in patients with early RA has not been reported. The primary objective of this subanalysis, therefore, was to evaluate the inhibition of radiological damage over 2 years in the early RA cohort of the ATTRACT study.

\section{METHODS}

The details of the ATTRACT study have been published previously. ${ }^{31-33}$

\section{Patients}

Patients whose data were included in this subanalysis comprised a cohort from the ATTRACT study of patients with RA of 3 years or less. The eligibility criteria in the ATTRACT study required patients to have active RA despite treatment with at least $12.5 \mathrm{mg}$ MTX a week.

\section{Study protocol}

In the ATTRACT study, patients were randomly assigned to one of five treatment groups. All patients continued with the same dose of MTX that they had received before enrolling in this study. One group received placebo infusions q 4 weeks, and the other groups received infliximab infusions in the

Abbreviations: ATTRACT, Anti-TNF Therapy in RA with Concomitant Therapy; DMARD, disease modifying antirheumatic drug; MTX, methotrexate; RA, rheumatoid arthritis; SDD, smallest detectable difference; TNF, tumour necrosis factor 
following regimens: $3 \mathrm{mg} / \mathrm{kg}$ q 8 weeks, $3 \mathrm{mg} / \mathrm{kg}$ q 4 weeks, $10 \mathrm{mg} / \mathrm{kg}$ q 8 weeks, or $10 \mathrm{mg} / \mathrm{kg}$ q 4 weeks. Patients receiving infliximab q 8 weeks received placebo infusions at interim visits. Randomisation was not stratified by disease duration. A protocol amendment to extend study treatment from 54 weeks to 102 weeks ( 2 years) was made after initiation of the trial. The details for this change in the protocol have been previously published. ${ }^{33}$

\section{Evaluation of radiographic data}

The modified van der Heijde (vdH)-Sharp score consists of a total of joint erosion scores and joint space narrowing scores. ${ }^{34}{ }^{35}$ Assessment of structural damage was measured by the change from baseline in the total modified radiographic score at week 102 . The variable analysed was the average of the total modified vdH-Sharp score provided by the two readers at week 102 minus the average of the two baseline scores. The readers scored the radiographs "blindly" and in random order. Radiographs of joints that had undergone surgery before enrolment were considered unevaluable. Patient scores were adjusted for the number of missing joints by dividing the missing joints by the number of joints assessed and then multiplying by the number of joints in the full joint set. Data for patients were excluded as a result of an incomplete set of $x$ ray pictures or an insufficient number of evaluable joints due to prior surgery or poor image quality. Radiographic progression rate at baseline was calculated as the total radiological score at baseline divided by the duration of disease in years.

Two different approaches were used to define radiological progression of disease: firstly, based on a change in progression greater than the smallest detectable difference (SDD), and secondly, as a change in progression exceeding 0.5. Assuming no evidence of bias, the SDD for the mean changes from baseline for two readers for each patient's radiographs was 1.96 (the standard deviation of the perpatient differences between the readers divided by the square root of 2). Any patient with a mean change from baseline larger than this value (based on the $95 \%$ limits of agreement from the estimate of the size of the random measurement error in this study) was considered to have progressed. ${ }^{36}$

Three separate analyses were conducted to assess the proportion of patients whose erosion scores had improved. The first analysis assessed the proportion of patients who demonstrated a change from baseline in erosion scores of less than -0.5 at week $102 .^{37}$ The second analysis examined the proportion of patients with a change from baseline in erosion scores of less than -0.5 and no worsening in the erosion score of any joint greater than 1. The third analysis for negative change examined the proportion of patients with a change from baseline in erosion scores less than -0.5 and no worsening in the erosion score in any joint.

\section{Statistical analysis}

The changes in the radiographic score were compared among the treatment groups by using analysis of variance of van der Waerden normal scores. The proportions of patients with increases of more or less than a given threshold value, such as the SDD in the total modified vdH-Sharp score, were compared among the treatment groups by a two sided Fisher's exact test at $\alpha=0.05$. If there was a significant overall treatment effect $(\alpha=0.05)$, comparisons of each infliximab treatment group with the placebo group were made using the linear contrasts with analysis of variance. All $\mathrm{p}$ values are nominal, and no adjustments were made for multiplicity.

\section{RESULTS}

Patient description and baseline characteristics

Four hundred and twenty eight patients were enrolled in the ATTRACT study. Eighty two patients were identified as having RA for 3 years or less. As part of the overall ATTRACT study, all patients who completed treatment up to week 54 were given the opportunity to continue in the study up to week 102 . Forty seven $(57 \%)$ of the 82 patients with early RA continued with the second year of treatment. Eighteen (38\%) of the 47 patients who continued had a treatment gap at some time during the second year compared with 29 (62\%) patients who had a treatment gap of no more than 8 weeks.

Table 1 presents the demographics for patients with early RA and for all patients in the ATTRACT study. The baseline and demographic characteristics of the group with early RA did not differ substantially from the overall population except for disease duration and extent of joint damage. The predicted progression rate at baseline for this group with early RA (11.3) was higher than that of the overall population (7.3) (table 1).

Of the 82 patients with early RA, 61 (74\%) had adequate radiographs for analysis. In the placebo group, 12 of 17 patients with early RA were evaluated. This includes seven patients who left the study at 54 weeks and five patients who completed 102 weeks of treatment. In the infliximab groups, 49 of 65 patients with early RA were evaluated. This includes 23 patients who left the study after 54 weeks and 26 patients who completed 102 weeks of treatment. The remaining 21 patients had either unreadable or missing radiographs at week 102.

\section{Prevention of structural damage}

At week 102, substantial progression of structural damage was observed for patients with early RA treated with MTX only; whereas, the change from baseline in radiographic scores for each infliximab plus MTX group was significantly less (fig 1). Moreover, when progression in structural damage for patients with early RA who were receiving MTX alone was compared with that for all patients in the ATTRACT study who were receiving MTX only, more rapid progression of disease was noted (almost threefold) (fig 1). Despite this, treatment with infliximab plus MTX inhibited radiographic

Table 1 Median baseline demographics for all ATTRACT patients and patients with early RA

\begin{tabular}{lll}
\hline Demographics & $\begin{array}{l}\text { All patients } \\
\text { (n=428) }\end{array}$ & $\begin{array}{l}\text { Patients with } \\
\text { early RA } \\
\text { ( } \mathbf{n = 8 2})\end{array}$ \\
\hline Age (years) & 54 & 50 \\
Sex, No (\%) & $332(78)$ & $65(79)$ \\
$\quad$ Female & $96(22)$ & $17(21)$ \\
$\quad$ Male & 8.4 & 1.7 \\
Duration of disease (years) & 31 & 30 \\
Tender joint count & 20 & 20 \\
Swollen joint count & 6.8 & 6.3 \\
Pain (1-10) & 120 & 120 \\
Morning stiffness (min) & 1.8 & 1.7 \\
HAQ (1-3) & 6.3 & 5.9 \\
Patient global assessment (1-10) & 6.3 & 5.9 \\
Evaluator global assessment (1-10) & 26 & 26 \\
CRP (mg/l) & 42.0 & 46.0 \\
ESR (mm/1st h) & 15 & 15 \\
MTX dose (mg) at baseline & & \\
Radiographic scores & 51.5 & 18.0 \\
VdH-Sharp score & 23.5 & 8.9 \\
$\quad$ Erosion score & 28.3 & 10.0 \\
Joint space narrowing score & 7.3 & 11.3 \\
Rate of progression* & & \\
\hline
\end{tabular}

Results are shown as the median value unless indicated otherwise. *Calculated by dividing the radiographic score at baseline by the duration of disease in years. 


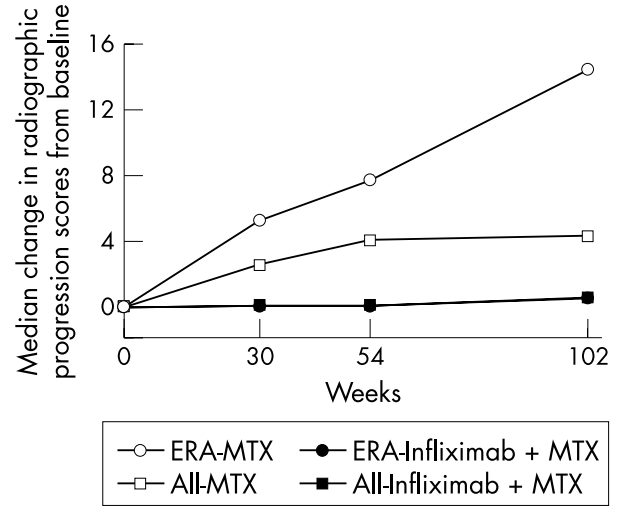

Figure 1 Median change in total radiographic score from baseline to week 102 for all patients with RA (All) v patients with early RA (ERA) who were randomised to MTX only (MTX) or infliximab plus MTX (Infliximab+MTX) in ATTRACT (disease duration $\leqslant 3$ years).

damage comparably in the early RA group and the overall infliximab treated population. A consistent benefit was also seen in the erosion and joint space narrowing scores of the hands and feet at week 102 in each of the four infliximab treatment groups compared with that of the MTX-only group (table 2). It is of interest to note that the lowest infliximab dosage regimen, $3 \mathrm{mg} / \mathrm{kg}$ q 8 weeks, produced results comparable with all the infliximab groups collectively (figs 2 and 3 ).

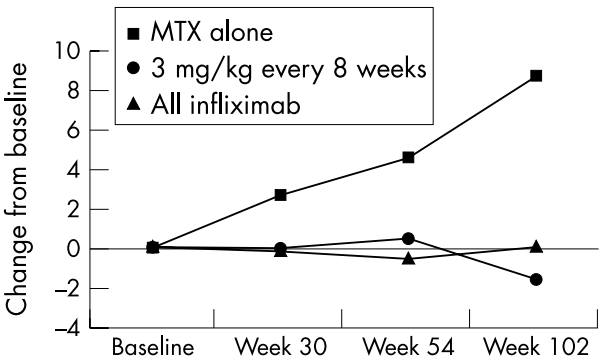

Figure 2 Median change in erosion scores from baseline to week 102 for patients with early RA in ATTRACT (disease duration $\leqslant 3$ years).

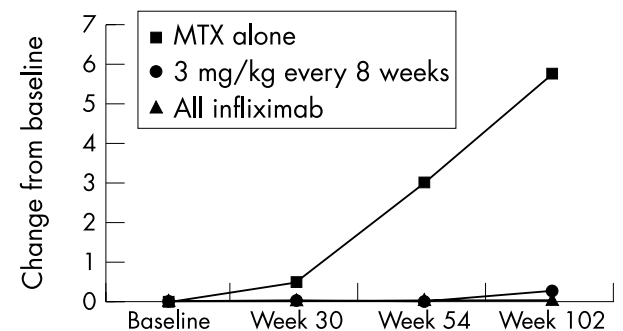

Figure 3 Median change in joint space narrowing scores from baseline to week 102 for patients with early RA in ATTRACT (disease duration $\leqslant 3$ years).

Table 2 Changes from baseline in erosion and joint space narrowing scores of the hands and feet at week 102 in patients with early RA

\begin{tabular}{|c|c|c|c|c|c|c|}
\hline \multirow[b]{2}{*}{ Assessment variable } & \multirow[b]{2}{*}{ MTX-only } & \multicolumn{2}{|c|}{$3 \mathrm{mg} / \mathrm{kg}$ Infliximab+MTX } & \multicolumn{2}{|c|}{$10 \mathrm{mg} / \mathrm{kg}$ Infliximab+MTX } & \multirow[b]{2}{*}{ Total infliximab } \\
\hline & & q 8 Weeks & q 4 Weeks & q 8 Weeks & q 4 Weeks & \\
\hline Patients randomised & 88 & 86 & 86 & 87 & 81 & 340 \\
\hline Patients with early RA & 17 & 19 & 19 & 20 & 7 & 65 \\
\hline Patients evaluated & 12 & 10 & 16 & 17 & 6 & 49 \\
\hline \multicolumn{7}{|l|}{$\begin{array}{l}\text { Erosion scores } \\
\text { Total }\end{array}$} \\
\hline Mean (SD) & $12.21(13.32)$ & $-1.02(2.49)$ & $-1.07(6.05)$ & $0.46(1.90)$ & $-0.78(2.81)$ & $-0.49(3.89)$ \\
\hline $\begin{array}{l}\text { Median } \\
\text { IQR } \\
\text { p Value } v \text { placebo }\end{array}$ & $\begin{array}{l}8.71 \\
(1.50,19.77)\end{array}$ & $\begin{array}{l}-1.63 \\
(-2.00,-0.50) \\
<0.001\end{array}$ & $\begin{array}{l}0.00 \\
(-1.25,1.25) \\
<0.001\end{array}$ & $\begin{array}{l}0.50 \\
(0.00,1.00) \\
<0.001\end{array}$ & $\begin{array}{l}-0.85 \\
(-1.98,1.00) \\
<0.001\end{array}$ & $\begin{array}{l}0.00 \\
(-1.70,1.00) \\
<0.001\end{array}$ \\
\hline \multicolumn{7}{|l|}{$\begin{array}{l}\text { p value V praceioo } \\
\text { Hands }\end{array}$} \\
\hline Mean (SD) & $5.67(6.17)$ & $-0.67(1.71)$ & $-0.78(4.70)$ & $0.22(1.82)$ & $-1.13(2.73)$ & $-0.45(3.10)$ \\
\hline Median & 4.21 & -0.38 & 0.00 & 0.00 & -0.99 & 0.00 \\
\hline IQR & $(0.00,9.81)$ & $(-2.41,0.50)$ & $(-1.25,0.27)$ & $(-0.50,1.00)$ & $(-2.20,1.00)$ & $(-1.50,0.50)$ \\
\hline $\mathrm{p}$ Value $v$ placebo & & $<0.001$ & 0.001 & 0.005 & 0.003 & $<0.001$ \\
\hline \multicolumn{7}{|l|}{ Feet } \\
\hline Mean (SD) & $6.54(7.87)$ & $-0.35(2.43)$ & $-0.28(1.56)$ & $0.24(1.12)$ & $0.35(0.44)$ & $-0.04(1.55)$ \\
\hline Median) & 4.50 & -0.25 & 0.00 & 0.00 & 0.25 & 0.00 \\
\hline IQR & $(1.25,7.75)$ & $(-1.50,0.50)$ & $(-0.25,0.50)$ & $(0.00,0.50)$ & $(0.00,0.50)$ & $(-0.50,0.50)$ \\
\hline $\mathrm{p}$ Value $v$ placebo & & $<0.001$ & $<0.001$ & $<0.001$ & 0.008 & $<0.001$ \\
\hline \multicolumn{7}{|c|}{ Total joint space narrowing scores } \\
\hline Mean (SD) & $12.82(15.73)$ & $0.39(6.24)$ & $-1.44(4.21)$ & $1.21(3.42)$ & $-0.61(2.09)$ & $-0.05(4.30)$ \\
\hline Median & & 0.21 & 0.00 & 0.00 & -1.38 & \\
\hline IQR & $(1.25,26.58)$ & $(-2.00,2.00)$ & $(-3.20,0.69)$ & $(0.00,2.50)$ & $(-1.93,-0.50)$ & $(-1.93,1.00)$ \\
\hline $\mathrm{p}$ Value $v$ placebo & & 0.002 & $<0.001$ & 0.010 & 0.002 & $<0.001$ \\
\hline \multicolumn{7}{|l|}{ Hands } \\
\hline Mean (SD) & 7.71 (11.71) & $0.94(5.53)$ & $-0.75(3.47)$ & $0.65(2.78)$ & $-0.43(2.09)$ & $0.12(3.61)$ \\
\hline Median & 3.25 & 0.25 & 0.00 & 0.00 & -1.07 & 0.00 \\
\hline IQR & $(0.00,9.83)$ & $(-1.50,2.00)$ & $(-1.70,0.69)$ & $(0.00,0.50)$ & $(-1.93,0.00)$ & $(-0.50,0.50)$ \\
\hline $\mathrm{p}$ Value $v$ placebo & & 0.051 & 0.008 & 0.031 & 0.009 & 0.003 \\
\hline \multicolumn{7}{|l|}{ Feet } \\
\hline Mean (SD) & $5.11(7.63)$ & $-0.55(2.31)$ & $-0.69(1.82)$ & $0.56(1.09)$ & $-0.19(0.45)$ & $-0.17(1.66)$ \\
\hline Median & 4.00 & 0.00 & 0.00 & 0.00 & 0.00 & 0.00 \\
\hline IQR & $(0.00,6.00)$ & $(0.00,0.00)$ & $(0.00,0.00)$ & $(0.00,0.50)$ & $(0.00,0.00)$ & $(0.00,0.00)$ \\
\hline $\mathrm{p}$ Value $v$ placebo & & $<0.001$ & $<0.001$ & 0.012 & 0.003 & $<0.001$ \\
\hline
\end{tabular}




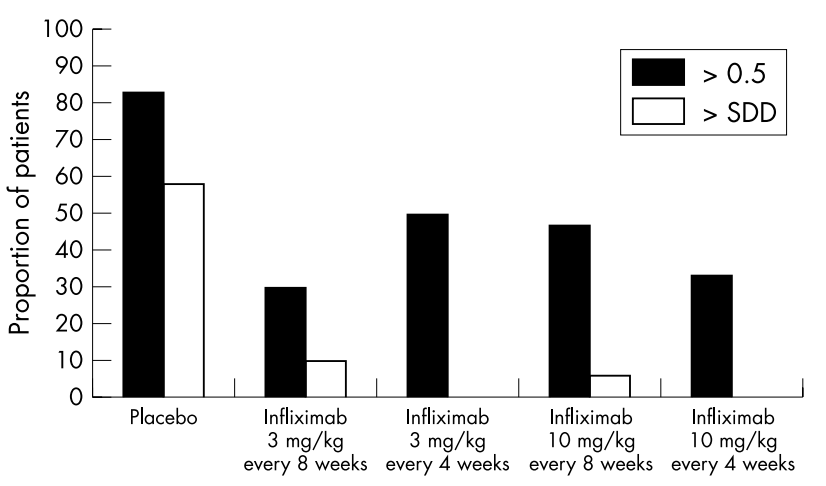

Figure 4 Proportions of patients with change $>$ SDD and change $>0.5$ from baseline in modified van der Heijde-Sharp score at week 102. $p=0.069$ for $3 \mathrm{mg} / \mathrm{kg}$ every 4 weeks $v$ placebo, $>0.5$ cut off criteria. $\mathrm{p}<0.05$ infliximab $\vee$ placebo for all other comparisons.

The use of quantitative cut off points can facilitate a more meaningful interpretations of small changes in radiographic films. Regardless of whether progression is defined by a change greater than 0.5 or a change greater than the SDD, a noticeably greater proportion of patients in the MTX-only group experienced progression in the total radiographic score than the proportions in the infliximab plus MTX groups (fig 4). Significant benefit with infliximab plus MTX therapy was seen in erosion and joint space narrowing scores when changes greater than 0.5 or greater than the SDD, respectively, were evaluated (tables 3 and 4).

We next examined the proportion of patients who demonstrated improvement from baseline in erosion scores at week 102 (table 5). A greater proportion of patients $(p=0.004)$ who received any dose of infliximab plus MTX demonstrated improvement from baseline in erosion scores of at least -0.5 at week 102 than patients who received MTX only.

Similar findings were demonstrated in two analyses that used more stringent criteria for improvement (table 5). The proportion of patients with a change from baseline in the erosion score of less than -0.5 and no worsening in the erosion score (greater than 1 in any joint) was also evaluated. A significantly $(p \leqslant 0.008)$ greater proportion of infliximab plus MTX treated patients who received 3 and $10 \mathrm{mg} / \mathrm{kg}$ infliximab every 4 weeks (7/16 (44\%) patients and 3/6 (50\%) patients, respectively) and $3 \mathrm{mg} / \mathrm{kg}$ every 8 weeks (7/10 (70\%) patients) met this criterion compared with that in the MTXonly group $(0 / 12(0 \%)$ patients); however, the numbers in each group were very small. The most stringent analysis for negative change examined the proportion of patients with a change from baseline in erosion score of less than -0.5 and no worsening in erosion score in any joint. A significantly greater proportion $(\mathrm{p} \leqslant 0.034)$ of patients who received 3 and $10 \mathrm{mg} / \mathrm{kg}$ infliximab every 4 weeks (5/16 (31\%) patients and $2 / 6(33 \%)$ patients, respectively) met this criterion at week 102 than patients in the MTX-only group $(0 / 12(0 \%)$ patients).

\section{DISCUSSION}

Of the 428 patients with RA enrolled in the ATTRACT study, 82 patients were identified post hoc as having disease for a duration of 3 years or less. Of these 82 patients, radiographs were available for 61 patients. The remaining 21 patients either had missing or unreadable radiographs. The ATTRACT patients with early RA who received MTX only had substantially greater radiographic progression over 102 weeks than the overall ATTRACT population. Accordingly, this population may represent a subset of patients who had very progressive disease, as suggested by the incomplete response to MTX. We also observed that the overall predicted yearly radiographic progression for the patients with early RA at baseline was 11.3 compared with 7.3 for all patients, again reflecting a population with more aggressive RA. Notably, however, the current findings are consistent with the results of a study which monitored the development of radiological damage of patients during the first 6 years of disease. That study demonstrated a mean annual rate of progression according to the modified vdHSharp score of 8.6 in 502 patients. ${ }^{38}$ Of note, modified vdHSharp scores increased dramatically at week 102 in patients with early RA treated with MTX only compared with patients treated with MTX only whose disease onset varied (all patients).

Despite the more rapid, predicted progression rate in patients with early RA, the results consistently demonstrated a significantly $(p \leqslant 0.005)$ smaller proportion of patients in the infliximab plus MTX group who experienced progression in radiographic score than patients in the MTX-only group. Notably, radiographic scores increased dramatically over

Table 3 Patients with change $>0.5$ from baseline in erosion and joint space narrowing scores of the hands and feet at week 102

\begin{tabular}{|c|c|c|c|c|c|c|}
\hline \multirow[b]{2}{*}{ Assessment variable } & \multirow[b]{2}{*}{ MTX-only } & \multicolumn{2}{|c|}{$3 \mathrm{mg} / \mathrm{kg}$ Infliximab+MTX } & \multicolumn{2}{|c|}{$10 \mathrm{mg} / \mathrm{kg}$ Infliximab+MTX } & \multirow[b]{2}{*}{ Total infliximab } \\
\hline & & q 8 Weeks & q 4 Weeks & q 8 Weeks & q 4 Weeks & \\
\hline Patients with early RA (n) & 17 & 19 & 19 & 20 & 7 & 65 \\
\hline Patients evaluated ( $n$ ) & 12 & 10 & 16 & 17 & 6 & 49 \\
\hline \multicolumn{7}{|l|}{ Erosion score } \\
\hline Total erosion score $>0.5$ & $10(83)$ & $1(10)$ & $6(38)$ & $6(35)$ & $2(33)$ & $15(31)$ \\
\hline $\mathrm{p}$ Value $v$ placebo & & 0.002 & 0.023 & 0.022 & 0.107 & 0.002 \\
\hline Hands & $8(67)$ & $2(20)$ & $3(19)$ & $5(29)$ & $2(33)$ & $12(24)$ \\
\hline $\mathrm{p}$ Value $v$ placebo & & 0.043 & 0.019 & 0.067 & 0.321 & 0.013 \\
\hline Feet & $10(83)$ & $2(20)$ & $2(13)$ & $4(24)$ & $1(17)$ & $9(18)$ \\
\hline$p$ Value $v$ placebo & & 0.008 & $<0.001$ & 0.003 & 0.013 & $<0.001$ \\
\hline \multicolumn{7}{|l|}{ Joint space narrowing } \\
\hline Total joint space narrowing $>0.5$ & $10(83)$ & $4(40)$ & $4(25)$ & $6(35)$ & $1(17)$ & $15(31)$ \\
\hline $\mathrm{p}$ Value $v$ placebo & & 0.074 & 0.006 & 0.022 & 0.013 & $<0.002$ \\
\hline Hands & $8(66)$ & $4(40)$ & $4(25)$ & $3(18)$ & $1(17)$ & $12(24)$ \\
\hline $\mathrm{p}$ Value $v$ placebo & & 0.391 & 0.053 & 0.018 & 0.131 & 0.013 \\
\hline Feet & $8(67)$ & $2(20)$ & $1(6)$ & $4(24)$ & $0(0)$ & $7(14)$ \\
\hline $\mathrm{p}$ Value $v$ placebo & & 0.043 & 0.001 & 0.029 & 0.013 & $<0.001$ \\
\hline
\end{tabular}


Table 4 Patients with a change $>S D D$ from baseline in erosion (SDD $=7.4)$ and joint space narrowing (SDD $=6.1)$ scores of the hands and feet at week 102

\begin{tabular}{|c|c|c|c|c|c|c|}
\hline \multirow[b]{2}{*}{ Assessment variable } & \multirow[b]{2}{*}{ MTX-only } & \multicolumn{2}{|c|}{$3 \mathrm{mg} / \mathrm{kg}$ Infliximab+MTX } & \multicolumn{2}{|c|}{$10 \mathrm{mg} / \mathrm{kg}$ Infliximab+MTX } & \multirow[b]{2}{*}{ Total Infliximab } \\
\hline & & q 8 Weeks & q 4 Weeks & q 8 Weeks & q 4 Weeks & \\
\hline Patients with early RA & 17 & 19 & 19 & 20 & 7 & 65 \\
\hline Patients evaluated & 12 & 10 & 16 & 17 & 6 & 49 \\
\hline \multicolumn{7}{|l|}{ Erosions $S D D=7.4$} \\
\hline Total erosion score & $7(58)$ & $0(0)$ & $0(0)$ & $0(0)$ & $0(0)$ & $0(0)$ \\
\hline $\mathrm{p}$ Value $v$ placebo & & 0.005 & $<0.001$ & $<0.001$ & 0.038 & $<0.001$ \\
\hline Hands & $6(50)$ & $0(0)$ & $1(6)$ & $1(6)$ & $0(0)$ & $2(4)$ \\
\hline $\mathrm{p}$ Value $v$ placebo & & 0.015 & 0.023 & 0.011 & 0.054 & $<0.001$ \\
\hline Feet & $3(25)$ & $0(0)$ & $0(0)$ & $0(0)$ & $0(0)$ & $0(0)$ \\
\hline $\mathrm{p}$ Value $v$ placebo & & 0.221 & 0.067 & 0.060 & 0.515 & 0.006 \\
\hline \multicolumn{7}{|c|}{ Joint space narrowing (JSN) SDD $=6.1$} \\
\hline Total JSN score & $6(50)$ & $1(10.0)$ & $0(0)$ & $1(6)$ & $0(0)$ & $2(4)$ \\
\hline$p$ Value $v$ placebo & & 0.074 & 0.002 & 0.011 & 0.54 & $<0.001$ \\
\hline Hands & $4(33)$ & $1(10.0)$ & $0(0)$ & $1(6)$ & $0(0)$ & $2(4)$ \\
\hline$p$ Value $v$ placebo & & 0.323 & 0.024 & 0.130 & 0.245 & 0.011 \\
\hline Feet & $7(58)$ & $0(0.00)$ & $0(0)$ & $1(6)$ & $0(0)$ & $1(2)$ \\
\hline$p$ Value $v$ placebo & & 0.005 & $<0.001$ & 0.003 & 0.038 & \\
\hline
\end{tabular}

102 weeks in patients treated early with MTX only when compared with the entire group of ATTRACT patients treated with MTX only. In contrast, radiographic scores remained unchanged over 102 weeks in patients treated with any regimen of infliximab plus MTX. These data indicate that TNF blockage is effective in both early and more established RA, as has been previously suggested. ${ }^{27}$

A sufficient number of changes from baseline for erosion and joint space narrowing scores were negative, thereby resulting in negative means and medians. The implication of these negative scores is unclear, but may be consistent with the probability that healing occurs.

We also chose to analyse the data from the early RA cohort using the more rigorous SDD criteria. There was more significant and consistent benefit with infliximab plus MTX treatment in the proportion of patients experiencing progression in erosion and joint space narrowing scores in the hands and feet, with respect to changes greater than the SDD. In fact, very few patients treated with infliximab showed a progression rate greater than the SDD.

The early RA cohort analysed was small, and the ATTRACT trial was not originally designed or powered to perform this study. There are a number of other limitations inherent in this analysis. The subgroup was not generated by random assignment and may not have had uniform baseline disease characteristics and disease prognosis. Seventy one per cent
(12/17) of the patients in the MTX-only group and 63\% (12/ 19) of the patients in the $3 \mathrm{mg} / \mathrm{kg}$ q 8 weeks group did not continue treatment into the second year. Radiographs were available for only $53 \%$ (10/19) of the patients in the $3 \mathrm{mg} / \mathrm{kg}$ q 8 weeks infliximab plus MTX group. A greater number of available radiographs for this treatment group would have provided more support for the analyses, as this was the apparently least beneficial dosage of infliximab plus MTX. Of the 65 patients treated with any regimen of infliximab, 49 patients $(75 \%)$ had available radiographs at week 102 . Finally, multiple comparisons were performed with no adjustments in $\mathrm{p}$ values. These limitations must be considered when interpreting the results. ${ }^{39}$ Future studies are warranted that are powered by design to analyse an early RA cohort.

The potential impact of anti-TNF therapy in early RA may centre on its ability to abort or dampen the proinflammatory cascade at a stage before other inflammatory cytokines and effectors are up regulated. There is emerging evidence to support the practice of using aggressive treatment in early RA to alter the course of the disease. Data suggesting the success of very early, aggressive treatment with infliximab have also been reported. ${ }^{28}{ }^{29}$ The results of the studies suggest that treatment of early RA with infliximab combined with MTX may prove to have a sustained, synergistic effect; although, longer trials with more patients are needed.

Table 5 Patients with radiographic improvement (negative change) in erosion of the hands and feet at week 102 in patients with early RA

\begin{tabular}{|c|c|c|c|c|c|c|}
\hline \multirow[b]{2}{*}{ Assessment variable } & \multirow[b]{2}{*}{ MTX only } & \multicolumn{2}{|c|}{$3 \mathrm{mg} / \mathrm{kg}$ Infliximab+MTX } & \multicolumn{2}{|c|}{$10 \mathrm{mg} / \mathrm{kg}$ Infliximab+MTX } & \multirow[b]{2}{*}{ Total infliximab } \\
\hline & & q 8 Weeks & q 4 Weeks & q 8 Weeks & q 4 Weeks & \\
\hline Patients with early RA & 17 & 19 & 19 & 20 & 7 & 65 \\
\hline Patients evaluated & 12 & 10 & 16 & 17 & 6 & 49 \\
\hline Patients with score $<-0.5$ & $0(0)$ & $7(70)$ & $7(44)$ & $3(18)$ & $3(50)$ & $20(41)$ \\
\hline $\mathrm{p}$ Value $v$ placebo & & $<0.001$ & 0.010 & 0.246 & 0.025 & 0.006 \\
\hline $\begin{array}{l}\text { Patients with score }<-0.5 \\
\text { and no worsening in any joint } \\
\text { of }>1\end{array}$ & $0(0)$ & $7(70)$ & $7(44)$ & $3(18)$ & $3(50)$ & $20(41)$ \\
\hline p Value $v$ placebo & & $<0.001$ & 0.010 & 0.246 & 0.025 & 0.006 \\
\hline $\begin{array}{l}\text { Patients with score }<-0.5 \\
\text { and no worsening in any joint }\end{array}$ & $0(0)$ & $2(20)$ & $5(31)$ & $3(18)$ & $2(33)$ & $12(24)$ \\
\hline $\mathrm{p}$ Value $v$ placebo & & 0.195 & 0.053 & 0.246 & 0.098 & 0.100 \\
\hline
\end{tabular}

Results are given as No (\%) of patients. 
The results demonstrate that infliximab, in combination with MTX therapy, arrested the progression of structural damage in a significant proportion of patients in this small cohort with early, aggressive disease. Not only did the combination of infliximab and MTX prevent progressive joint damage during the first year of treatment but also, in some cases, the radiographic joint damage improved, signifying that some damage may have been repaired. ${ }^{32}$ However, the results of this exploratory analysis are not conclusive, and thus, must be regarded as preliminary. This analysis is retrospective, and the cohort is small. However, the results for radiographic progression are particularly striking, given the strong evidence of benefit despite the small numbers of patients in each regimen.

In summary, the data from this cohort of patients with early RA suggest that in patients with rapid disease progression, early treatment may produce substantially better results than treatment begun later in the course of the disease. Further controlled studies are warranted to examine this issue.

\section{ACKNOWLEDGEMENTS}

We thank Mary H Whitman and Patricia A Geraghty for their assistance in preparation of this manuscript.

Financial Support Information: Supported by Centocor, Malvern, Pa. $\mathrm{K}$ Patel is employed by Centocor, Inc, FC Breedveld, P Emery, E Keystone, DE Furst, JR Kalden, EW St Clair, M Weisman, J Smolen, and RN Maini (ATTRACT Study Group) have received grants or served as consultants to, or as members of, the speakers' bureau sponsored by Centocor or other companies that manufacture treatments for rheumatoid arthritis

\section{Authors' affiliations}

F C Breedveld, Department of Rheumatology, University of Leiden, Leiden, The Netherlands

P Emery, Academic Unit of Musculoskeletal Disease, Department of Rheumatology, University of Leeds, Leeds, UK

E Keystone, University of Toronto, Toronto, Canada

K Patel, Centocor, Inc., Malvern, PA, USA

D E Furst, University of California at Los Angeles, School of Medicine, Los Angeles, CA, USA

J R Kalden, Department of Internal Medicine III and Institute for Clinical Immunology, University Erlangen-Nuremberg, Germany

E W St Clair, Division of Rheumatology and Immunology, Duke University Medical Center, Durham, NC, USA

M Weisman, University of California at Los Angeles, School of Medicine, Los Angeles, CA, USA

J S Smolen, Department of Rheumatology, University of Vienna, and 2nd Department of Medicine, Lainz Hospital, Vienna, Austria

P E Lipsky, Intramural Research Program, National Institute of Arthritis and Musculoskeletal and Skin Diseases, Bethesda, MD, USA

R N Maini, The Kennedy Institute of Rheumatology and the Imperial College School of Medicine, London, UK

\section{REFERENCES}

1 Potter T, Mulherin D, Pugh M. Early intervention with disease-modifying therapy for rheumatoid arthritis: where do the delays occur? Rheumatology (Oxford) 2002;41:953-5

2 Emery P, Quinn M, Conaghan P. Reply to: Early intervention with diseasemodifying therapy for rheumatoid arthritis: where do the delays occur? Rheumatology (Oxford) 2002;41:955.

3 Moreland LW, Bridges SL. Early rheumatoid arthritis: a medical emergency? Am J Med 2001;111:498-500.

4 Sokka T. First visit to a rheumatologist of U.S. patients with early rheumatoid arthritis occurs after a median of 5 months of symptoms. Arthritis Rheum 2002;46(suppl 9):S543.

5 Aletaha D, Eberl G, Nell VPK, Machold KP, Smolen JS. Practical progress in realization of early diagnosis and treatment of patients with suspected rheumatoid arthritis: results from two matched questionnaires within three years. Ann Rheum Dis 2002;61:630-4.

6 Irvine S, Munro R, Porter D. Early referral, diagnosis and treatment of rheumatoid arthritis: evidence for changing medical practice. Ann Rheum Dis 1999;58:510-13

7 Emery P, Breedveld FC, Dougados M, Kalden JR, Schiff MH, Smolen JS. Early referral recommendation for newly diagnosed rheumatoid arthritis: evidence based development of a clinical guide. Ann Rheum Dis 2002;61:290-7.
8 Fuchs HA, Kaye JJ, Callahan LF, Nance EP, Pincus T. Evidence of significant radiographic damage in rheumatoid arthritis within the first 2 years of disease. J Rheumatol 1989;16:585-91.

9 van Everdingen AA, Jacobs JWG, Siewerrtsz van Reesema DR, Biilsma JWJ. Low-dose prednisone therapy for patients with early active rheumatoid arthritis: clinical efficacy, disease-modifying properties, and side effects: a randomized, double-blind, placebo-controlled clinical trial. Ann Intern Med 2002;136:1-12.

10 Lard LR, Visser H, Speyer I, van der Horst-Bruinsma IE, Zwinderman AH, Breedveld FC, et al. Early versus delayed treatment in patients with recentonset rheumatoid arthritis: comparison of two cohorts who received differen treatment strategies. Am J Med 2001;111:446-51.

11 Jeyaratnam R, Kerr LD, Spiera H, Crane RP, Pugh MT. A comparative analysis of the time taken from onset of symptoms of rheumatoid arthritis to initiation of disease modifying anti-rheumatic drugs at the Mount Sinai Hospital, USA and the Birmingham Heartlands Hospital, UK. Rheumatology (Oxford) 2001:40(suppl 1):29.

12 Gray M, Nuki G. Audit of delay between symptom onset and commencement of disease modifying anti-rheumatic drugs (DMARDs) in patients with newly diagnosed rheumatoid arthritis referred to a hospital rheumatology unit. Rheumatology (Oxford) 2001:40(Suppl 1):60.

13 Backhaus M, Burmester GR, Sandrock D, Loreck D, Hess D, Scholz A, et al. Prospective two year follow up study comparing novel and conventional imaging procedures in patients with arthritic finger joints. Ann Rheum Dis 2002;61:895-904.

14 McQueen FM, Benton N, Crabbe J, Robinson E, Yeoman S, McLean L, et al What is the fate of erosions in early rheumatoid arthritis? Tracking individual lesions using $x$-rays and magnetic resonance imaging over the first two years of disease. Ann Rheum Dis 2001;60:859-68.

15 Möttőnen T, Hannonen P, Korpela M, Nissilä M, Kautiainen $\mathrm{H}$, llonen J, et al. Delay to institution of therapy and induction of remission using single-drug or combination-disease-modifying antirheumatic drug therapy in early rheumatoid arthritis. Arthritis Rheum 2002;46:894-8.

16 Bukhari MAS, Wiles NJ, Lunt M, Harrison BJ, Scott DGI, Symmons DPM, et al Early DMARD therapy influences progression of radiographic damage in inflammatory polyarthritis: results from a five year population-based prospective study [abstract]. Arthritis Rheum 2001;44:S153.

17 Aletaha D, Smolen JS. The rheumatoid arthritis patient in the clinic: comparing more than 1300 consecutive DMARD courses. Rheumatology (Oxford) 2002;41:1367-74

18 Anderson JJ, Wells G, Verhoeven AC, Felson DT. Factors predicting response to treatment in rheumatoid arthritis. Arthritis Rheum 2000;43:22-9.

19 Hochberg MC. Early aggressive DMARD therapy: the key to slowing disease progression in rheumatoid arthritis. Scand J Rheumatol 1999;28(suppl 112):3-7.

20 Stenger AAME, van Leeuwen MA, Houtman PM, Bruyn GAW, Speerstra F, Barendsen $B C$, et al. Early effective suppression of inflammation in rheumatoid arthritis reduces radiographic progression. $\mathrm{Br} J$ Rheumatol 1998;37: 1 157-63.

21 Kvien TK, Zeidler HK, Hannonen P, Wollheim FA, Førre $\varnothing$, Hafström I, et al. Long term efficacy and safety of cyclosporin versus parenteral gold in early rheumatoid arthritis: a three year study of radiographic progression, renal function, and arterial hypertension. Ann Rheum Dis 2002;61:511-16.

22 Bombardier C, Deaton RL, Gregersen P, Massarotti E, Formica C, Weisman MH. Pattern of DMARD use in a North American cohort of patients with early rheumatoid arthritis (RA) (SONORA) [abstract]. Arthritis Rheum 2002;46(suppl 9):S344.

23 Boers M, Verhoeven AC, Markusse HM, van de Laar MAFJ, Westhovens R, van Denderen JC, et al. Randomized comparison of combined step-down prednisolone, methotrexate and sulphasalazine with sulphasalazine alone in early rheumatoid arthritis. Lancet 1997;350:309-18.

24 van der Heide A, Jacobs JWG, Biilsma JWJ, Heurkens AHM, van BoomaFrankfort $C$, van der Veen MJ, et al. The effectiveness of early treatment with "second-line" antirheumatic drugs: a randomized, controlled trial. Ann Intern Med 1996;124:699-707.

25 Çalgüneri M, Pay S, Çalișkaner Z, Apras S, Kiraz S, Ertenli I, et al. Combination therapy versus monotherapy for the treatment of patients wtih rheumatoid arthritis. Clin Exp Rheumatol 1999;17:699-704.

26 Mulherin D, Fitzgerald O, Bresnihan B. Clinical improvement and radiological deterioration in rheumatoid arthritis: evidence that the pathogenesis of synovial inflammation and articular erosion may differ. $\mathrm{Br} J$ Rheumatol 1996:35:1263-8.

27 Bathon JM, Martin RW, Fleischmann RM, Tesser JR, Schiff MH, Keystone EC, et al. A comparison of etanercept and methotrexate in patients with early rheumatoid arthritis. N Enl J Med 2000;343:1586-93.

28 Taylor PC, Steuer A, Gruber J, McClinton C, Cosgrove D, Blomley M, et al. Infliximab attenuates joint destruction in early RA patients with ultrasonographic markers of poor prognosis [abstract]. Arthritis Rheum 2002;46(suppl 9):S334

29 Quinn MA, Conoghan PG, Greenstein A, Karim Z, Brown C, Emery P. Sustained response in early poor prognosis RA after withdrawal of infliximab therapy [abstract]. Arthritis Rheum 2002;46(suppl 9):LB03.

30 Zhang Z, Moreland LW, Bridges SL. Micromanipulation and single-cell PCR of immunoglobulin heavy chain rearrangements from lymphoid follicles in early rheumatoid arthritis (RA) synovium reveals oligoclonal B cell expansion [abstract]. Arthritis Rheum 1999;42(suppl 9):S389

31 Maini R, St Clair EW, Breedveld F, Furst D, Kalden J, Weisman M, et al. Infliximab (chimeric anti-tumour necrosis factor $\alpha$ monoclonal antibody) versus placebo in rheumatoid arthritis patients receiving concomitant methotrexate: a randomised phase III trial. Lancet 1999;354:1932-9. 
32 Lipsky PE, van der Heijde DMFM, St Clair EW, Furst DE, Breedveld FC, Kalden JR, et al. Infliximab and methotrexate in the treatment of rheumatoid arthritis. N Engl J Med 2000;343:1594-602.

33 Maini RN, Breedveld FC, Kalden JR, Smolen JS, Furst D, Weisman MH, et al. Sustained improvement in physical function, structural damage, and signs and symptoms through 2 years in rheumatoid arthritis patients treated with infliximab (Remicade) and methotrexate. Arthritis Rheum, (in press).

34 van der Heijde. How to read radiographs according to the Sharp/van der Heiide method. J Rheumatol 2000;27:261-3.

35 van der Heijde D, Dankert T, Nieman F, Boers M. Reliability and sensitivity to change of a simplification of the Sharp/van der Heijde radiological assessment in rheumatoid arthritis. Rheumatology (Oxford) 1999;38:941-7.
36 Lassere $M$, Boers $M$, van der Heiide D, Boonen A, Edmonds J, Saudan A, et al. Smallest detectable difference in radiological progression. J Rheumatol 1999;26:731-9.

37 van der Heiide D, Simon L, Smolen J, Strand V, Sharp J, Boers M, et al. How to report radiographic data in randomized clinical trials in rheumatoid arthritis: guidelines from a roundtable discussion. Arthritis Rheum 2002;47:215-18.

38 Hulsmans HMJ, Jacobs JWG, van der Heijde DMFM, van AlbadaKuipers GA, Schenk Y, Biilsma JWJ. The course of radiologic damage during the first six years of rheumatoid arthritis. Arthritis Rheum 2000:43:1927-40.

39 Assmann SF, Pocock SJ, Enos LE, Kasten LE. Subgroups analysis and other (mis)uses of baseline data in clinical trials. Lancet 2000;355:1064-9.

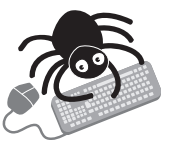

Please visit the Annals of the Rheumatic Diseases website [www. annrheumdis. com] for a link to the full text of this article.
Rofecoxib $v$ naproxen $v$ placebo in rheumatoid arthritis: gastroduodenal ulcer incidence

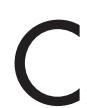

OX-2 inhibitors are as effective as non-selective NSAIDs and are well tolerated. Naproxen reduces prostaglandin synthesis in the gastric mucosa by $70 \%$ whereas rofecoxib has no effect. Endoscopic studies have shown that rofecoxib is associated with significantly less risk of upper gastrointestinal complications than are the non-selective drugs in patients with osteoarthritis. Similar findings have been reported in patients with rheumatoid arthritis. Now a large international study has produced similar results.

At 48 centres in 18 countries a total of 660 patients with rheumatoid arthritis were randomised to rofecoxib $50 \mathrm{mg}$ once daily, naproxen $500 \mathrm{mg}$ twice daily, or placebo for 12 weeks. Endoscopy was performed at baseline and at 6 and 12 weeks. Injectable or oral steroid treatment (equivalent to prednisone $10 \mathrm{mg}$ or less daily) was allowed. The incidence of gastroduodenal ulcers $3 \mathrm{~mm}$ or less in diameter by 12 weeks was significantly higher on naproxen $(25.5 \%)$ than on rofecoxib $(6.8 \%)$ or placebo $(2.9 \%)$. For naproxen $v$ rofecoxib $\mathrm{p}<0.001$, naproxen $v$ placebo $\mathrm{P}<0.001$, rofecoxib $v$ placebo $\mathrm{p}=0.066)$. Similar results were obtained using ulcers of $5 \mathrm{~mm}$ or more diameter or number of gastroduodenal erosions as end points. The cumulative incidence of ulcers of $3 \mathrm{~mm}$ or greater diameter at 12 weeks in $H$ pylori negative patients was 3.6\% (placebo), 3.9\% (rofecoxib), and 33.3\% (naproxen). For $H$ pylori positive patients the corresponding figures were $2.3 \%, 8.3 \%$, and $17.9 \%$. Adverse events were reported in $61.1 \%, 62.1 \%$, and $66.4 \%$ (no significant differences) and drug related adverse events in $25.8 \%, 35.6 \%$, and $39.5 \%$ (both active drugs significantly worse than placebo). Serious adverse events occurred in 2.7\%, $1.8 \%$, and $4.1 \%$ (no significant differences). Epigastric discomfort and discontinuation because of an adverse event were both significantly more frequent in the naproxen group but there were no significant group differences in the incidence of dyspepsia or heartburn. Perforation, ulcer, or bleeding (PUBs) occurred in 1/221 (placebo), 2/219 (rofecoxib), and 4/220 (naproxen). There was a small increase in hypertension ( $2.3 \%$ vs $6.4 \%$ vs $0.9 \%$ ) with rofecoxib but it usually had only minor clinical significance and no patient withdrew because of it.

Rofecoxib $50 \mathrm{mg}$ daily (twice the usual dose) caused less upper gastrointestinal upset than naproxen $500 \mathrm{mg}$ twice daily.

A Gut 2003;52:820-826. 